\title{
Biological and Phylogenetic Analyses Suggest that Two Cryphonectria spp. Cause Cankers of Eucalyptus in Africa
}

\author{
J. Roux, H. Myburg, B. D. Wingfield, and M. J. Wingfield, Department of Genetics, Forestry, and Agricultural \\ Biotechnology Institute (FABI), University of Pretoria, Pretoria, South Africa
}

\begin{abstract}
Roux, J., Myburg, H., Wingfield, B. D., and Wingfield, M. J. 2003. Biological and phylogenetic analyses suggest that two Cryphonectria spp. cause cankers of Eucalyptus in Africa. Plant Dis. 87:1329-1332.

Cryphonectria cubensis is an economically important pathogen of commercial Eucalyptus spp. Differences have been reported for disease symptoms associated with Cryphonectria canker in South Africa and other parts of the world, and recent DNA-based comparisons have confirmed that the fungus in South Africa is different from that in South America and Australasia. During a disease survey in the Republic of Congo, Cryphonectria canker was identified as an important disease on Eucalyptus grandis and E. urophylla. In this study, we compared Congolese and South African isolates of $C$. cubensis using DNA sequence data and pathogenicity under greenhouse conditions. The $\beta$-tubulin and internal transcribed spacer (ITS) region sequences show that $C$. cubensis in Congo is different from the fungus in South Africa and that Congolese isolates group most closely with South American isolates. Furthermore, pathogenicity tests showed that a South African isolate was more aggressive than two Congolese isolates. We conclude that two distinct Cryphonectria spp. occur in Africa and hypothesize that the fungus in the Congo probably was introduced into Africa from South America. Both fungi are important pathogens causing disease and death of economically important plantation trees. However, they apparently have different origins and must be treated separately in terms of disease management and quarantine considerations.
\end{abstract}

Cryphonectria cubensis (Bruner) C. S. Hodges is an economically important canker pathogen of plantation-grown Eucalyptus spp. in many tropical and subtropical countries $(2,7,11,18,26)$. Cryphonectria canker has been described from Eucalyptus spp. in Australia, Brazil, Colombia, India, South Africa, Surinam $(5,7,11,18,26)$, and a number of other countries. The disease results in stem cankers that often lead to the death of affected trees and has necessitated the development of extensive breeding programs to reduce its impact $(1,4)$.

Cryphonectria canker in South Africa and the disease in South America, Southeast Asia, and Australasia display different symptoms. In South Africa, infection results in cankers at the base and root collars of trees, resulting in the rapid wilt and death of young trees ( $<18$ months old). Infection on older trees results in cracking of the bark at the base of trees, resulting in

Corresponding author: J. Roux

E-mail: Jolanda.roux@fabi.up.ac.za

Funding was provided by the National Research Foundation (NRF), members of the Tree Pathology Co-operative Programme (TPCP), and the THRIP initiative of the Department of Trade and Industry, South Africa.

Accepted for publication 1 June 2003.

Publication no. D-2003-0911-01R

(C) 2003 The American Phytopathological Society the formation of swollen "skirts" of bark $(3,4,26)$. Furthermore, the South African fungus causes cankers that are restricted mostly to the cambium. In South America and Southeast Asia, C. cubensis results in diffuse cankers that occur on the stems and around branch stubs (11). These cankers girdle trees, resulting in stem breakage at the points of infection. Cankers in South Africa typically are covered by pycnidia of C. cubensis, and the teleomorph has been reported only once. In South America and Southeast Asia, cankers are most commonly covered with perithecia of $C$. cubensis $(22,25)$.

Previously, it was shown that South African isolates of $C$. cubensis are more closely related to those in South America than to Australasian isolates (15). However, recent DNA-based comparisons using multiple genes have shown that the fungus causing Cryphonectria canker in South Africa also is different from that in South America (14). Using $\beta$-tubulin and histone H3 gene sequences, Myburg et al. (14) showed that the South American and Australasian fungi reside in related, well-defined but separate clades. Furthermore, the South African fungus resides in a distinct, well-defined clade of its own (14). These differences and the differing disease symptoms led Myburg et al. $(13,14)$ to conclude that more than one species of fungus is responsible for Cryphonectria canker of Eucalyptus spp. These and other authors also have suggested that $C$. cubensis is distantly related to other species of Cryphonectria and might better be accommodated in a new genus $(13,14,23,27)$.

During the course of a survey of diseases in Eucalyptus plantations in the Republic of Congo (Brazzaville) in 1998, Cryphonectria canker was observed on $E$. grandis and E. urophylla trees near Point Noire in the west of the country (17). Symptoms of the disease were similar to those found in South America, with the formation of stem cankers and not basal cankers, as in South Africa. The aim of this study was to compare isolates of the fungus from Congo with those from other parts of the world. This was achieved using sequence data from two regions of the $\beta$ tubulin gene and the internal transcribed spacer (ITS) regions, including the 5.8S gene, of the rRNA operon. Pathogenicity of isolates from the Republic of Congo and those from South Africa also were compared in a greenhouse test.

\section{MATERIALS AND METHODS}

Fungal isolates. The isolates studied (Table 1) represented $C$. cubensis from various parts of the world and also the related chestnut blight fungus (6), C. parasitica (Murrill) Barr. An isolate from the Democratic Republic of the Congo (Zaire), previously identified as $C$. havanensis (CMW10453) and obtained from R. J. Stipes (Virginia Polytechnic Institute and State University, Blacksburg), also was included. Diaporthe ambigua Nits., a canker pathogen of pome and stone fruit trees (19), was included as the outgroup taxon.

DNA isolation, polymerase chain reaction amplification, and sequencing. Fungal cultures were grown in $2 \%$ malt extract broth (Biolab) and harvested after a week. DNA isolations were done as described by Myburg et al. (15). Polymerase chain reaction (PCR) amplification and sequencing of the ITS 1, ITS 2, and 5.8S region of the ribosomal RNA operon, as well as two regions within the $\beta$-tubulin gene, were done using the following primer pairs: ITS 1 and ITS 4 (24), Bt1a and Bt1b (9), and $\mathrm{Bt} 2 \mathrm{a}$ and $\mathrm{Bt} 2 \mathrm{~b}$ (9). Amplification conditions were the same as those described in Myburg et al. (14,15).

The PCR products were sequenced in both directions using the same primers as used for PCR. Sequence reactions were run on an ABI PRISM 377 automated DNA sequencer using the ABI PRISM Dye Terminator Cycle Sequencing Ready Reaction 
Kit with AmpliTaq DNA Polymerase, FS (Perkin-Elmer, Warrington, UK). DNA sequences were aligned using CLUSTAL $X$ (21), and the alignments were adjusted manually.

Both $\beta$-tubulin and ITS DNA sequences were viewed using the software package Sequence Navigator (version 1.0.1; PerkinElmer Applied BioSystems, Inc., Foster City, CA). This program also was used to translate the $\beta$-tubulin sequences into putative amino acid sequences and to determine the conserved exon and variable intron sites for $C$. cubensis, C. parasitica, and D. ambigua. $\beta$-Tubulin data were compared with the amino acid sequence of Neurospora crassa Shear \& B.O. Dodge (GenBank accession no. M13630) (16).

Phylogenetic analyses were performed using Phylogenetic Analysis Using Parsimony (PAUP, version 4.0b; 20). A partition-homogeneity test (PHT) was performed between ITS and $\beta$-tubulin gene data sets. Parsimony analyses were done via heuristic search options with the branch swapping algorithm (tree-bisection-reconnection) and MULTREES (saving all optimal trees) options effective. Gaps were treated as fifth characters (NEWSTATE). A bootstrap analysis (1,000 replications) was done to determine the confidence levels of the branching points for the generated trees. The sequences generated in this study were deposited in GenBank (Table 1).

Pathogenicity tests. A known pathogenic isolate of $C$. cubensis from South Africa (CMW2113) (22) and two isolates from the Republic of Congo (CMW10671 and CMW10672) were selected to compare their pathogenicity in greenhouse trials. The two Congolese isolates were selected from isolates collected in 1998 as being the most aggressive in a pilot trial using the same technique as that described below. Twenty trees of an E. grandis clone (ZG14) known to be susceptible to Cryphonectria canker in South Africa were used for each treatment in each of two trials. These trees were approximately 1

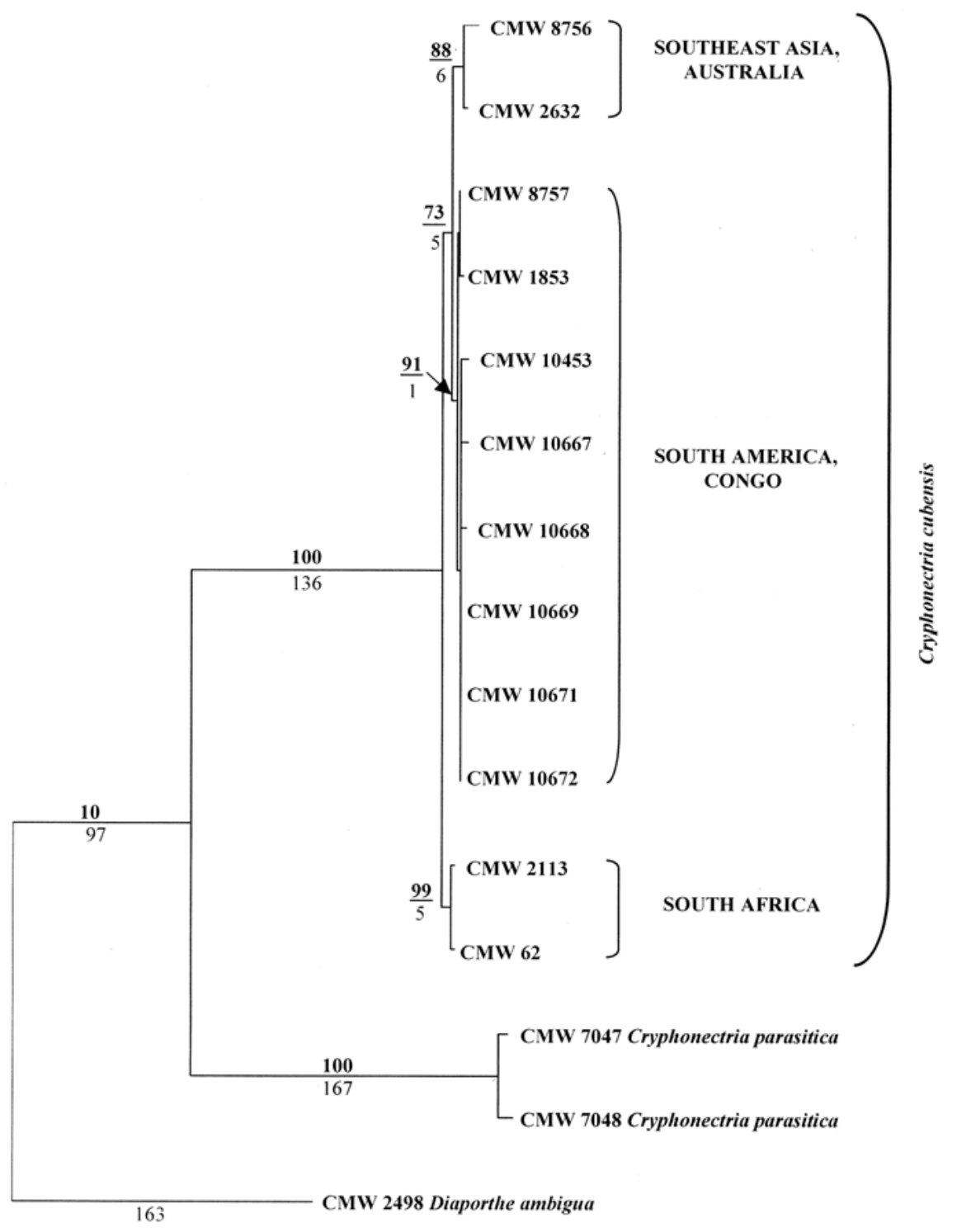

Fig. 1. One of two trees (tree length $=627$ steps, consistency index $=0.97$, retention index $=0.96$ ) generated from heuristic searches performed on a combined sequence data set including the internal transcribed spacer regions of the ribosomal DNA and $\beta$-tubulin sequences. Diaporthe ambigua was used as the outgroup. Branch lengths (base substitutions) are indicated below the branches and bootstrap values above.

Table 1. Hosts, geographic origin, and GenBank accession numbers of isolates used for phylogenetic and pathogenicity studies

\begin{tabular}{|c|c|c|c|c|}
\hline Species & Culture no. ${ }^{a}$ & Origin & Host & GenBank accession numbers ${ }^{b}$ \\
\hline Cryphonectria cubensis & CMW 62 & South Africa & Eucalyptus grandis & AF 292041, AF273063, AF273458 \\
\hline C. cubensis & CMW 1853 & Brazil & Syzygium aromaticum & AF046891, AF273070, AF273465 \\
\hline C. cubensis & CMW 2113 & South Africa & E. grandis & AF046892, AF273067, AF273462 \\
\hline C. cubensis & CMW 2632 & Australia & E. marginata & AF046893, AF273078, AF375607 \\
\hline C. cubensis & CMW 8756 & Indonesia & E. marginata & AF046896, AF273077, AF375606 \\
\hline C. cubensis & CMW 8757 & Venezuela & Eucalyptus sp. & AF046897, AF273069, AF273464 \\
\hline C. cubensis $^{\mathrm{c}}$ & CMW 10667 & Republic of Congo & Eucalyptus sp. & AY063477, AY063479, AY063481 \\
\hline C. cubensis $^{\mathrm{c}}$ & CMW 10668 & Republic of Congo & Eucalyptus sp. & AF535121, AF535123, AF535125 \\
\hline C. cubensis $^{\mathrm{c}}$ & CMW 10669 & Republic of Congo & Eucalyptus sp. & AF535122, AF535124, AF535126 \\
\hline C. cubensis $^{\mathrm{c}}$ & CMW 10671 & Republic of Congo & Eucalyptus sp. & AY254219, AY254221, AY254223 \\
\hline C. cubensis $^{\mathrm{c}}$ & CMW 10672 & Republic of Congo & Eucalyptus sp. & AY254220, AY25422, AY254224 \\
\hline C. cubensis (C. havanensis) & CMW 10453 & Democratic Republic of Congo & E. saligna & AY063476, AY063478, AY063480 \\
\hline Cryphonectria parasitica & CMW 7047 & United States & Quercus virginiana & AF292042, AF273073, AF273469 \\
\hline C. parasitica & CMW 7048 & United States & Q. virginiana & AF292043, AF273076, AF273470 \\
\hline Diaporthe ambigua & CMW 2498 & Netherlands & Malus sylvestris & AF046906, AF273072, AF273471 \\
\hline
\end{tabular}

${ }^{\mathrm{a}}$ All isolates are housed in the culture collection of the Forestry and Agricultural Biotechnology Institute (FABI), University of Pretoria, South Africa.

b Accession numbers for internal transcribed spacer regions and $\beta$-tubulin sequences.

${ }^{\mathrm{c}}$ Isolates sequenced in this study. 
$\mathrm{cm}$ in diameter at the time of inoculation. Inoculation trials were conducted in a contained greenhouse at approximately $25^{\circ} \mathrm{C}$ with alternate day and night lighting. cambium, was used in the first set of inoculations; in a repeat trial, wounds were 9 $\mathrm{mm}$ in diameter. An agar plug of equal size, overgrown with the test fungus, was inserted into the wound with the mycelium facing the cambium. The wounds and inoculum were covered with Parafilm "M" laboratory film (American National Can, Chicago) to prevent desiccation. Results were recorded 4 weeks after inoculation. For the control inoculations, sterile agar plugs were used. One-way analysis of variance (ANOVA) was performed on the two separate data sets, and differences among treatments were computed using the General Linear Model (GLM) in SAS (SAS Institute, Cary, NC). Both Bonferroni and Dunnett's $t$ tests were conducted on the two separate data sets to compare all four treatments with each other in all possible combinations.

\section{RESULTS}

DNA amplification and sequencing. Amplification of the ITS 1 and ITS 2 (including the conserved 5.8S region) and the two $\beta$-tubulin regions generated PCR products of sizes 620 and $550 \mathrm{bp}$, respectively. Positions of introns and exons of the $\beta$-tubulin gene regions were compared against those of $N$. crassa (GenBank accession no. M13630), and insertions or deletions of coding regions were observed.

The PHT of 500 replicates generated a $P$ value of 0.68 , indicating that the ITS and $\beta$-tubulin data sets could be phylogenetically analyzed as a combined data set. In all, 1,492 characters were included for each taxon in the combined data set. Within this data set, 995 characters were constant, 182 variable characters were parsimony-uninformative, and 315 variable characters were parsimony-informative. The heuristic search produced two parsimonious trees of similar topology. One of the trees (tree length $=627$ steps, consistency index $=0.97$, rescaled consistency index $=0.94$, and retention index $=0.96$ ) is shown (Fig. 1).

The phylogenetic tree separated $C$. cubensis isolates from $C$. parasitica and
A 6-mm-diameter wound, exposing the

from $D$. ambigua, the root taxon. The $C$. cubensis branch node was supported by a bootstrap value of $100 \%$. Within the $C$. cubensis clade, three separate clades were seen. These clades agree with those published by Myburg et al. (13): isolates from Australasia (bootstrap support $=88 \%$ ), those from Congo and South America (bootstrap support $=91 \%$ ), and isolates from South Africa (bootstrap support = 99\%). The C. cubensis isolates from the Congo grouped with an isolate that had been identified as $C$. havanensis (CMW 10453) from the Democratic Republic of Congo.

Pathogenicity tests. The South African C. cubensis isolate (CMW2113) produced significantly $(P<0.0001)$ longer lesions in inoculated trees than did the Congolese isolates (CMW10671 and CMW10672; Table 2). Results of the Bonferroni and Dunnett's $t$ tests showed that there were statistically significant $(P=0.05)$ differences between the South African isolate (CMW2113) and the two Congolese isolates. The Congolese isolates also differed significantly from the control, but not from each other $(P=0.05)$. Many of the trees inoculated with the South African isolate were producing epicormic shoots below the point of inoculation when the experiments were terminated after 4 weeks. However, symptoms associated with the Congo and South African isolates were similar.

\section{DISCUSSION}

It has been shown recently that the fungus known as $C$. cubensis in South Africa is different from that causing cankers on Eucalyptus spp. in Australasia and South America (14). We assumed that the fungus in other parts of Africa would be the same as that in South Africa. However, results of this study have shown that the fungus associated with Cryphonectria canker in Congo is more similar to C. cubensis in South America.

The first record of Cryphonectria spp. from the African continent was in 1960, from the Democratic Republic of Congo (Zaire; 8). This isolate had been designated as $C$. havanensis but later was shown to be C. cubensis by Micales et al. (12). It was not until 20 years later that $C$. cubensis was reported formally from Africa, when

Table 2. Lesion lengths (mm) in Eucalyptus grandis inoculated in two trials with Cryphonectria cubensis isolates from South Africa and the Republic of Congo

\begin{tabular}{lccccc}
\hline & \multicolumn{2}{c}{ First inoculation $^{\mathbf{a}}$} & & \multicolumn{2}{c}{ Second inoculation $^{\mathbf{b}}$} \\
\cline { 2 - 3 } \cline { 6 - 6 } Isolates & Means & Confidence limits & & Means & Confidence limits \\
\hline CMW2113 (South Africa) & 156.75 & $144.71-168.79$ & & 160.79 & $152.88-168.52$ \\
CMW10671 (Congo) & 58.50 & $46.46-70.54$ & & 42.25 & $34.43-50.07$ \\
CMW10672 (Congo) & 61.90 & $49.86-73.94$ & & 39.5 & $31.68-47.32$ \\
Control & 6.0 & $-6.04-18.04$ & & 13.4 & $5.58-21.22$ \\
\hline
\end{tabular}

${ }^{a}$ Coefficient of variance $(\mathrm{CV})=36.41, R^{2}=0.82, P<0.0001$, confidence limit at $95 \%$, and standard error \pm 5.8 .

${ }^{\mathrm{b}} \mathrm{CV}=27.94, R^{2}=0.91, P<0.0001$, confidence limit at $95 \%$, and standard error \pm 3.9 .
Gibson (8) reported the fungus in young $E$. urophylla stands in Cameroon. The isolate from Congo collected in 1960 was deposited in the Centraalbureau voor Schimmelcultures, and this isolate has DNA sequences identical to those of isolates from the Republic of Congo, which neighbors the Democratic Republic of Congo. The similarity of the DNA sequences of isolates from Central Africa to those from South America suggests that the fungus in Central Africa was introduced from South America. However, more isolates and population studies would be necessary to test this hypothesis.

Greenhouse inoculation trials showed that the $C$. cubensis isolate from South Africa was more aggressive than the two selected isolates of the fungus from the Congo. All three isolates had been selected to represent the most aggressive isolates available from the two countries. These results have important implications for the Eucalyptus spp. improvement programs, not only in the Congo, but also in South America and Australasia. Clearly, the fungus in South Africa presents a threat to countries where it currently does not occur. The fact that a fungus of the same name occurs in many of these countries is likely to detract from the importance of this matter. Furthermore, South American and Central African $C$. cubensis causes a disease different to that currently known in South Africa, and every effort also should be made to exclude this fungus from South Africa.

The taxonomy of $C$. cubensis is currently undergoing revision. It has previously been suggested that this important pathogen is native to Asia, where it occurs on clove (Syzigium aromaticum, Myrtaceae; 10). Recently, C. cubensis was reported from native Tibouchina spp. (Melastomataceae) in Colombia (25) and exotic Tibouchina spp. in South Africa (13). This has led to a suggestion that the fungus might be native to South America, where it spread from native $\mathrm{Me}$ lastomataceae genera to Eucalyptus spp. (14). DNA sequence data have shown that C. cubensis from South Africa is distinct from the fungus of the same name, occurring elsewhere in the world. Thus, it will be important to determine the origin of the fungus in South Africa, and research is currently underway to resolve this question.

\section{ACKNOWLEDGMENTS}

We thank B. Eisenberg for the statistical analysis of the inoculation data.

\section{LITERATURE CITED}

1. Alfenas, A. C., Jeng, R., and Hubbes, M. 1983. Virulence of Cryphonectria cubensis on Eucalyptus species differing in resistance. Eur. J. For. Pathol. 13:179-205.

2. Boerboom, J. H. A., and Maas, P. W. Th. 1970. Canker of Eucalyptus grandis and E. saligna in Suriname caused by Endothia havanensis. Turrialba 20:94-99. 
3. Conradie, E., Swart, W. J., and Wingfield, M. J. 1990. Cryphonectria canker of Eucalyptus, an important disease in plantation forestry in South Africa. S. Afr. For. J. 152:43-49.

4. Conradie, E., Swart, W. J., and Wingfield, M. J. 1992. Susceptibility of Eucalyptus grandis to Cryphonectria cubensis. Eur. J. For. Pathol. 22:312-315.

5. Davison, E. M., and Tay, C. S. 1983. Twig, branch and upper trunk cankers of Eucalyptus marginata. Plant Dis. 67:1285-1287.

6. Elliston, J. E. 1981. Hypovirulence and chestnut blight research: fighting disease with disease. J. For. 79:657-660.

7. Florence, E. J., Sharma, J. K., and Mohanan, C. 1986. A stem canker disease of Eucalyptus caused by Cryphonectria cubensis in Kerala. In Eucalyptus in India: Past, Present and $\mathrm{Fu}-$ ture, 1986. Kerala For. Res. Inst. Sci. Pap. No. 66:384-387.

8. Gibson, I. A. S. 1981. A canker disease of Eucalyptus new to Africa. FAO, Forest Genet. Res. Inform. 10:23-24.

9. Glass, N. L., and Donaldson, G. C. 1995. Development of primer sets designed for use with the PCR to amplify conserved genes from filamentous ascomycetes. Appl. Environ. Microbiol. 61:1323-1333.

10. Hodges, C. S., Alfenas, A. C., and Cordell, C. E. 1986. The conspecificity of Cryphonectria cubensis and Endothia eugeniae. Mycologia 78:334-350.

11. Hodges, C. S., Reis, M. S., Ferreira, F. A., and Henfling, J. D. M. 1976. O cancro do eucalipto causado por Diaporthe cubensis. Fitopatol. Bras. 1:129-170.
12. Micales, J. A., Stipes, R. J., and Bonde, M. R. 1987. On the conspecificity of Endothia eugeniae and Cryphonectria cubensis. Mycologia 79:707-720.

13. Myburg, H., Gryzenhout M., Heath R., Roux J., Wingfield B. D., and Wingfield M. J. 2002. Cryphonectria canker on Tibouchina in South Africa. Mycol. Res. 106:1299-1306.

14. Myburg, H., Gryzenhout, M., Wingfield, B. D., and Wingfield, M. J. 2002. $\beta$-tubulin and Histone $\mathrm{H} 3$ gene sequences distinguish Cryphonectria cubensis from South Africa, Asia and South America. Can. J. Bot. 80:590-596.

15. Myburg, H., Wingfield, B. D., and Wingfield, M. J. 1999. Phylogeny of Cryphonectria cubensis and allied species inferred from DNA analysis. Mycologia 91:243-250.

16. Orbach, M. J., Porro, E. B., and Yanofsky, C. 1986. Cloning and characterization of the gene for beta-tubulin from a benomyl-resistant mutant of Neurospora crassa and its use as dominant marker. Mol. Cell. Biol. 6:2452-2461.

17. Roux, J., Wingfield, M. J., Coutinho, T. A., Bouillett, J. P., and Leigh, P. 1999. Diseases of plantation Eucalyptus in the Republic of the Congo. S. Afr. J. Sci. 96:454-456.

18. Sharma, J. K., Mohanan, C., and Maria Florence, E. J. 1985. Occurrence of Cryphonectria canker disease of Eucalyptus in Kerala, India. Ann. Appl. Biol. 106:265-276.

19. Smit, W. A., Viljoen, C. D., Wingfield, B. D., Wingfield, M. J., and Calitz, F. J. 1996. A new canker disease of apple, pear, and plum rootstocks caused by Diaporthe ambigua in South Africa. Plant Dis. 80:1331-1335.

20. Swofford, D. L. 1998. PAUP*. Phylogenetic
Analysis Using Parsimony (*and other methods). Version 4.0, Beta version. Sinauer Associates, Sunderland, MA.

21. Thompson, J. D., Gibson, T. J., Plewniak, F. Jeanmougin, F., and Higgins, D. G. 1997. The CLUSTAL W windows interface: flexible strategies for multiple sequence alignment aided by quality analysis tools. Nucleic Acids Res. 25:4876-4882.

22. Van Heerden, S. W., and Wingfield, M. J. 2001. Genetic diversity of Cryphonectria cubensis isolates in South Africa. Mycol. Res. 105:94-99.

23. Venter, M., Wingfield, M. J., Coutinho, T. A., and Wingfield, B. D. 2001. Molecular characterisation of Endothia gyrosa isolates from Eucalyptus in South Africa and Australia. Plant Pathol. 50:211-217.

24. White, T. J., Bruns T., Lee, S., and Taylor, J. 1990. Amplification and direct sequencing of fungal ribosomal RNA genes for phylogenetics. Pages 315-322 in: PCR Protocols: A Guide to Methods and Applications. Academic Press, San Diego, CA.

25. Wingfield, M. J., Rodas, C., Myburg, H. Venter, M., Wright, J., and Wingfield, B. D. 2001. Cryphonectria canker on Tibouchina in Colombia. For. Pathol. 31:1-10.

26. Wingfield, M. J., Swart, W. J., and Abear, B. J. 1989. First record of Cryphonectria canker of Eucalyptus in South Africa. Phytophylactica 21:311-313.

27. Zhang, N., and Blackwell, M. 2001. Molecular phylogeny of dogwood anthracnose fungus (Discula destructiva) and the Diaporthales. Mycologia 93:355-365. 